\title{
Construct Validation Study of Web-Based Kuder's Preference Records 2011-Version
}

\author{
P. Tommy Y. S. Suyasa ${ }^{1 *}$ Indah Setiawan ${ }^{1}$ Zamralita Zamralita $^{1}$ \\ Wasino Wasino ${ }^{2}$ Nathanael Osbert Auda ${ }^{1}$
}

\author{
${ }^{1}$ Faculty of Psychology, Universitas Tarumanagara, Jakarta 11440, Indonesia \\ ${ }^{2}$ Faculty of Information Technology, Universitas Tarumanagara, Jakarta 11440, Indonesia \\ *Corresponding author. Email: tommys@fpsi.untar.ac.id
}

\begin{abstract}
The web-based Kuder's Preference Records 2011-version (KPR V.2011) is an instrument for measuring ten vocational interests. These ten vocational interests are: artistic, social service, literary, clerical, scientific, musical, outdoor, mechanical, persuasive, and computational. The purpose of this study is to conduct a construct validation study (convergent evidence) and profiling vocational interest. The number of participants in this study was 264. Participants were students from various majors, namely: arts, social science, literary, finance, law, health science, natural science, engineering, communication/business sciences, information \& computing engineering, and administration/management. The instruments used to test the construct validation study (convergent evidence) is the Holland's Vocational Preference Inventory and Big Five Personality (NEO-PI). Authors did a vocational interest profiling for students majoring in social science. This research provides three findings. First, KPR V.2011 shares a convergent evidence of personality traits (Big Five Personality, NEO-PI). Second, KPR V.2011 also shares convergent evidence with Holland's Vocational Preference Inventory (VPI), especially in relevant areas. Third, social service, computational, and musical are the most preferred vocational interests for students majoring in social science. Discussions on the three findings will be discussed further.
\end{abstract}

Keywords: Vocational interest, kuder preference records, holland's vocational preference, personality, academic achievement

\section{INTRODUCTION}

Various problems (psychological problems, academic problems, relational problems) are experienced by students when they choose a major in university [1]. When students take majors that are not suitable for their interests and abilities, students show feelings of resentment, sadness, or lack of enthusiasm in undergoing lectures. Likewise, in the results of studies achieved to be less optimal, students become difficult to understand the material, unable to be independent in learning, which leads to a low-performance index. Because of the under-achievement conditions, students have the potential to experience feelings of inferiority, which in turn can make them withdraw or even not continue their studies.

In order to avoid mistakes in the selection of majors, prospective students need to understand their interests. It might be that the mistake in choosing a major because prospective students do not understand the major they are interested in. Therefore, the interest held by prospective students needs to be measured systematically and objectively through psychological measurement methods. Measurement of interest systematically and objectively can be assisted by psychologists by using measuring instruments/psychological instruments.

In the psychological practice, there are at least three most commonly used interest measurement tools. The three measuring tools for this area of interest are Strong's Interest Inventory (SII), Kuder's Preference Records (KPR), and Holland's Self-Directed Search/Preference Vocational Inventory (VPI). Each measuring instrument has advantages and disadvantages.

Campbell [2] acknowledged that Kuder's Preference Records had advantages compared to SII, "He noted the Kuder's Verification scale as a temporary feature and found that the Kuder's Preference Records had the edge over Strong in being shorter and having simpler scoring" [2, p. 691]. Although Campbell in 1965 criticized that KPR did not have predictive validity information, in 1974, information on predictive validity was immediately published. The study, which was conducted on 1,800 participants over the 25 years used, Form C KPR (full version KPR, ten areas of interest, 168 set items, 1948), was able to predict $60 \%$ of participant career choices [3]. Compared to Holland's VPI, it appears that the area of interest measured by the KPR has more coverage. KPR measures 10 areas of interest, while Holland's VPI 
measures 6 areas of interest. Six areas of interest measured in Holland's VPI are: realistic, investigative, artistic, social, enterprising, and conventional, shortened to RIASEC. The ten areas of interest measured in KPR are: artistic, social service, literary, clerical, scientific, musical, mechanical, outdoor, persuasive, and computation. Although the ten aspects of the area of interest measured in the KPR do not reflect all the majors/ study programs available in various universities in Indonesia, but if it will be used for majors in universities, it appears that 10 aspects of the area of interest measured by KPR appear to cover more area compared to Holland's VPI.

KPR have weaknesses or have the potential to have low face validity. KPR has 168 sets (504 alternative items). This amount has the potential to be tiring for test participants to complete it, especially if accompanied by other tests/ assessments. To overcome the low potential of face validity, Suyasa [4] summarizes 504 items (KPR) to 200 items (KPR V.2011). All KPR V.2011 items have convergence evidence with the original version of the KPR (504 items). It is expected that the KPR V.2011 can overcome face validity problems (it seems tiring for test participants because the number of items is too many).

Until now, information on the validity of the KPR V.2011 has not been explained. Based on the research [5], [6], it was explained that the results of the area of interest should relate to personality trait. For example: the area of artistic interest is positively correlated with openness to experience; or the area of social interest is positively related to agreeableness. In a validation study of personality trait constructs (Big Five Personality), Barrick et al. [5] and Wille et al. [6] using Holland's VPI as a measure of areas of interest. The KPR V.2011 as a measure of the area of interest, should also have construct validity on personality trait.

The KPR V.2011 does not yet have information on construct validity evidence and discriminant evidence with Holland's VPI. Not yet explained which areas of interest from KPR V.2011 measure the same areas of interest as measured by Holland's VPI; and which areas of interest from KPR V.2011 not measured by Holland's VPI. If KPR V.2011 has convergence and discriminant evidence with Holland's VPI, it can be said that KPR V.2011 has several more areas of interest than Holland's VPI.

To facilitate KPR V.2011 validation process, a web-based KPR V.2011 was compiled. Web-based KPR V.2011 can be easily reached by various groups, without requiring additional paper and pencil instruments. But the ease of web-based access may become a weakness. If there are participants who do not have access to the web, then the candidate party is difficult to participate. In this study, there are planned results of the construct validity (convergence evidence) testing of the KPR V.2011 measurement on personality trait constructs (Big Five Personality) [7] and construct convergence evidence and discriminant evidence on other areas of interest (Holland's VPI). As preliminary study of criterion validity measurement of the KPR V.2011, this study will descibe interest profile of participants from the social sciences. In this study, the number of participants in the major of social sciences was identified the most compared to participants from other majors.

\section{BACKGROUND}

\subsection{Interests and Personality}

Interest and personality are two concepts with different constructs, but still interrelated. Personality describes an individual's tendency to show feelings, thoughts, or display general behavior (in various situations). While interest in explaining thoughts, feelings, and behavioral choices in a specific scope, especially work/activities related to work [5], [8], [9]. Although personality and interest are different constructs, personality and interest have several similarities. Holland [10, p. 8] states that interest is an expression of personality (interests are expressions of personality). Interest and personality are the basis of motivation to behave. Interest and personality are stable over time [11], although various variations of activities experienced can influence the formation of individual interests [12]. Wille et al. [6] state that several interests (Holland) area scores correlate with personality (NEO-PI). Realistic interest scale, no significant associations with any of the Big Five traits are observed. Investigative interests are positively correlated with Openness to experience, Conscientiousness, and negatively correlated with Neuroticism and Agreeableness. Artistic interests are positively correlated with Openness and Neuroticism; negatively with Conscientiousness. Social interests are positively correlated with Neuroticism, Openness, and Agreeableness; and slightly negatively with Conscientiousness. Enterprising interests, positive associations were found with Extraversion, Openness, and Conscientiousness; and negative associations with Neuroticism, and Agreeableness. Conventional interests are positively correlated with Conscientiousness; negatively with Openness. Based on more or less the same logic, several areas of interest in KPR V.2011 will also have correlations with some personality trait.

H1: The measurement results of KPR V.2011 have construct validity (convergent evidence) with personality trait.

\subsection{Kuder's Preference Record (KPR) and Holland's Vocational Preference Inventory}

Although the areas of interest measured in the KPR and Holland's Vocational Preference Inventory (VPI) are different, the measurement results from the two inventories will be interconnected. In previous studies [13], the Occupational Interest Survey (Kuder OIS) was stated to have a similar structure to Holland's VPI. Thus, it can be expected that the KPR measurement results will correlate with Holland's VPI measurement results, especially in some regions of interest. Holland's VPI measures six aspects of areas of interest, namely: Realistic, 
Investigative, Artistic, Social, Enterprising, and Conventional. While KPR measures ten areas of interest, namely: artistic, social service, literary, clerical, scientific, musical, outdoor, mechanical, persuasive, and computational.

\subsubsection{Realistic and mechanical}

The indicators of Realistic interest measurement (Holland's VPI) include working as a technician, taking courses in repairing car engines, and working on machines; meanwhile the indicators of measurement of Mechanical interest (KPR V.2011), include: studying the contents of a computer machine, tinkering with equipment/machinery, and fixing electrical equipment. The higher the individual score in the area of realistic interest (Holland's VPI), the more indicators of the area of scientific interest that individuals choose (KPR V.2011).

\subsubsection{Investigative and scientific}

Indicators of Investigative interest (Holland's VPI) include reading articles with scientific titles, conducting various studies, and reading the results of research conducted by experts. Indicators of scientific interest measurement (KPR V.2011), include: becoming a member of an association of astronomers, conducting investigations on new types of drugs, and conducting experiments to obtain new types of fruits. The higher the individual score in the area of investigative interest (Holland's VPI), the more indicators of the area of scientific interest that individuals choose (KPR V.2011).

\subsubsection{Artistic and artistic}

Indicators of measuring Artistic interest (Holland's VPI) include visiting the painting exhibition, paying attention to works of art, and teaching art. Indicators for measuring artistic interest (KPR V.2011), include: taking drawing courses, becoming a photo painter, and teaching painting. The higher the individual scores in the area of Artistic interest (Holland's VPI), the more indicators of the area of artistic interest that individuals choose (KPR V.2011).

\subsubsection{Social and social service}

Indicators for measuring social (Holland's VPI) interests include working for charity activities, making charitable activities, and offering to help victims of natural disasters. Indicators for measuring interest in social services (KPR V.2011) include: teaching poor children, teaching Indonesian to illiterate mothers, and participating in community activities. The higher the individual score in the area of social interest (Holland's VPI), the more indicators of the area of social service interest that individuals choose (KPR V.2011).

\subsubsection{Enterprising and persuasive}

Enterprising (Holland's VPI) interest measurement indicators include seeking business opportunities, attending training on how to sell well, and obtaining opportunities in business. Indicators for measuring persuasive interest (KPR V.2011) include convincing others to buy a product, persuading others to buy a show ticket, and becoming a salesperson for a product. The higher the individual score in the area of enterprising interest (Holland's VPI), the more indicators of the area of persuasive interest that individuals choose (KPR V.2011).

\subsubsection{Conventional and clerical}

The indicators of Conventional interest (Holland), includes: tidying up letters, making financial records, and grouping letters based on their interests. Indicator for measuring clerical interest (KPR V.2011), includes: working on office administration, filing letters (documents), and becoming a secretary in a company. The higher the individual score in the area of conventional interest (Holland's VPI), the more indicators of the area of clerical interest chosen by the individual (KPR V.2011).

H2: The KPR V.2011 measurement results have construct validity (convergent evidence) with the results of the Holland's Vocational Preferences Inventory measurement.

\subsection{Kuder's Preference Record on Social Science Major}

Interest measurement is needed to predict success in choosing a major/study program. Person-Environment Fit Theory (PEFT) describes how interest can relate to student success in choosing a major/study program. PEFT is built on the theory of vocational choice [14]. Theory of vocational choice explains that individuals will choose an environment that is appropriate to their area of interest. While PEFT [15] explains that congruence, suitability, or similarity between the environment and the area of interest will influence individual behavior. PEFT predicts that the more suitable individuals are with their environment, the more individuals produce positive outcomes. The more individuals fit, congruent, or have similarities with their environment, the need-fulfilment process or the motivation growth process occurs. Motivated individuals try to find opportunities to improve their knowledge and skills, resulting in good outcomes. In the industrial/organisational context, the suitability of the area of interest of individuals with their fields of work predicts positive performance [16], [17].

For preliminary studies whether KPR V.2011 can predict success in choosing a major/study program, profiling will be carried out in this study. Participants from particular major/study program will express their various areas of interest. Some of the areas of interest that are the highest in the score are assumed to be the area of interest to be the basis for selecting majors/study programs. Thus, the area of interest that participants have in specific majors/study 
programs will be the initial information of their suitability for the choice of majors/study programs. Donnay and Borgen [18] state that the suitability of measurement results from an interest measuring instrument can be seen from the actual choice of field of work. By using the research analogy [18], the results of measurement of the area of interest of KPR V.2011 can be the basis for selecting the majors/study programs currently being pursued.

\section{METHODS}

\subsection{Participants}

This study involved 264 participants. Most participants were female $(n=193,73.1 \%)$. Participants' ages varied between 18 and 47 years $(M=30.88, \quad S D=8,267)$. Participants were mostly from social science majors $(n=100,37.9 \%)$ and the last education of participants were mostly bachelor degree $(n=180,68.2 \%)$.

\subsection{Measurements}

In this study, the measurement instruments used were: (a) Kuder's Preference Records 2011-Version (KPR V.2011), (b) Holland's RIASEC Interest Inventory (Holland's VPI), and (c) NEO PI-R.

\subsubsection{Kuder's preference records 2011-version (KPR V.2011)}

KPR V.2011 is a modification of the KPR measurement instruments. The total number of KPR V.2011 items is as many as 100 sets of items, with each of the two response choices representing area of interest. Thus, the overall measurement instrument consists of 200 statements. In the 200 items of the statement, 180 statements (18 items for each area) were used as items for measuring the interests of participants; 20 other statements (two items for each area) are used to test the consistency of participants' responses. An example of an item used to test consistency in artistic interest is "to arrange flowers" and "to become a painter". In administering the KPR V.2011, participants are asked to choose one of two response options. The response options represent one of the area of most significant interest by participants. The KPR V.2011 measures ten areas of interest, namely: artistic, social service, literary, clerical, scientific, musical, outdoor, mechanical, persuasive, and computational. Each psychometric information from these ten areas is described in the following paragraph.

The first area of interest, namely artistic; examples of items used to measure this area of interest are: "taking a drawing course", "being a photo painter", and "teaching painting". The eighteen items that measure this area of interest have internal consistency $(\alpha)$ of $=0.767$. The higher the score in this area of interest, the participants are increasingly interested in taking drawing courses, becoming a photo painter, or teaching painting.

The second area of interest, namely social service; examples of items used to measure this area of interest are "teaching disadvantaged children", "teaching Indonesian to illiterate mothers", and "participating in community activities". The eighteen items that measure this area of interest have internal consistency $(\alpha)$ of $=0.713$. The higher the score in this area of interest, the participants are increasingly interested in teaching poor children, teaching Indonesian to illiterate mothers, or participating in community activities.

The third area of interest, namely literary; examples of items used to measure this area of interest are "writing things that are experienced every day", "learning to write stories", and "writing articles to be published in magazines". The eighteen items that measure this area of interest have internal consistency $(\alpha)$ of $=0.694$. The higher the score in this area of interest, the more interested participants are to write things that are experienced every day, learn to write stories, or write articles to be published in magazines.

The fourth area of interest, namely clerical; examples of items used to measure this area of interest are "working on office administration", "filing letters (documents)", and "being a secretary in a company". The eighteen items that measure this area of interest have internal consistency $(\alpha)$ of $=0.766$. The higher the score in this area of interest, the more interested participants are to work on office administration, file letters (documents), or become secretaries in a company.

The fifth area of interest, namely scientific; examples of items used to measure this area of interest

are "becoming a member of an association of astronomers", "investigating new types of drugs", and "experimenting with new types of fruits". The eighteen items that measure this area of interest have internal consistency $(\alpha)$ of $=0.684$ The higher the score in this area of interest, the more participants are interested in becoming members of astronomers' associations, investigating new types of drugs, or conducting experiments to get the type new fruits.

The sixth area of interest, namely musical; examples of items used to measure this area of interest are "mastering several musical instruments", "deepening skills in music", and "establishing music schools". The eighteen items that measure this area of interest have internal consistency $(\alpha)$ of $=0.858$. The higher the score in this area of interest, the participants are increasingly interested in mastering several musical instruments, deepening skills in music, or establishing music schools.

The seventh area of interest, namely outdoor; examples of items used to measure this area of interest are "exploring caves", "camping in the wild", and "hiking (walking) in a hill". The eighteen items that measure this area of interest have internal consistency $(\alpha)$ of $=0.715$. The higher the score in this area of interest, the more interested participants are to explore caves, camping in the wild, or hiking (on foot) in a hilly area. 
The eighth area of interest, namely mechanical; examples of items used to measure this area of interest are "learning the contents of a computer machine", "tinkering with equipment/machinery, and "fixing electrical equipment". The eighteen items that measure this area of interest have internal consistency $(\alpha)$ of $=0.786$. The higher the score in this area of interest, the participants are increasingly interested in learning the contents of computer machines, tinkering with equipment/machines, or fixing electrical equipment.

Ninth area of interest, namely persuasive; Examples of items used to measure this area of interest are "convincing others to buy a product", "persuading others to buy a show ticket", and "becoming a salesperson for a product". The eighteen items that measure this area of interest have internal consistency $(\alpha)$ of $=0.770$. The higher the score in this area of interest, the more interested participants are to convince others to buy a product, persuade others to buy a show ticket, or become a salesperson for a product.

The tenth area of interest, namely computational; Examples of items used to measure this area of interest are "working on mathematical formulas", "becoming arithmatic experts", and "teaching arithmetic". The eighteen items that measure this area of interest have internal consistency $(\alpha)$ of $=0.863$. The higher the score in this area of interest, the more interested participants are to work with math formulas, become arithmetic experts, or teach arithmetic.

\subsubsection{Holland's vocational preferences inventory (VPI)}

The Holland's VPI is used to construct a validation study of the KPR V.2011 measuring instrument. This measuring instrument consists of six areas of interest, namely realistic, investigative, artistic, social, enterprising, and conventional. In each area of interest, it is measured using 14 items. Measurement information in each area of interest is outlined in the paragraph below.

The first area of interest, namely realistic; examples of items used to measure this area of interest are "working as a technician", "taking courses in repairing car engines", and "tinkering on machines". The fourteen items that measure this area of interest have internal consistency $(\alpha)$ of $=0.878$. The higher the score in this area of interest, the more interested participants are to work as technicians, take courses in repairing car engines, and tinkering with machines.

The second area of interest, namely the investigative; examples of items used to measure this area of interest are "reading articles with scientific titles", "conducting various studies", and "reading the results of research conducted by experts". The fourteen items that measure this area of interest have internal consistency $(\alpha)$ of $=$ 0.913. The higher the score in this area of interest, the more interested participants are to read articles that are scientific, conduct various studies, or read the results of research conducted by experts.
The third area of interest, namely artistic; examples of items used to measure this area of interest are "visiting the painting exhibition", "paying attention to works of art", and "teaching arts". The fourteen items that measure this area of interest have internal consistency $(\alpha)$ of $=0.907$. The higher the score in this area of interest, the more interested participants will be to visit the painting exhibition, pay attention to works of art, or teach art.

The fourth area of interest, namely social; examples of items used to measure this area of interest are "working for charity activities", "making charitable activities", and "offering to help victims of natural disasters". The fourteen items that measure this area of interest have internal consistency $(\alpha)$ of $=0.885$. The higher the score in this area of interest, the participants are increasingly interested in working for charity activities, making charitable activities, or offering themselves to help victims of natural disasters.

The fifth area of interest, namely enterprising; examples of items used to measure this area of interest are: "looking for business opportunities", "attending training on how to sell well", "and "gaining opportunities in business". The fourteen items that measure this area of interest have internal consistency $(\alpha)$ of $=0.919$. The higher the score in this area of interest, the more interested participants are to look for business opportunities, take training on how to sell well, or get the opportunity to do business.

The sixth area of interest, namely conventional; Examples of items used to measure this area of interest are "tidying up letters", "making financial records", and "grouping letters based on their interests". The eighteen items that measure this area of interest have internal consistency $(\alpha)$ of $=0.901$. The higher the score in this area of interest, the participants are increasingly interested in tidying up letters, making financial records, and grouping letters based on their significance.

\subsubsection{NEO PI-R}

Beside Holland's VPI, other measurement instruments used for KPR V.2011 construct validation study is NEO PI-R [7]. The author only uses 60 items from the total number of items totalling 240 items (Faculty of Psychology, Tarumanagara University, 2013). These sixty points represent five dimensions, namely openness, conscientiousness, extraversion, agreeableness, and neuroticism. Each dimension is measured by twelve items. Openness dimension; the example of the openness dimension is: "I love to discuss theories or ideas that are abstract", "I want to discuss various things (essence, history, explanation) about something", and "I am interested to read poetry or see a work of art". The twelve items in the openness dimension have internal consistency $(\alpha)$ of $=0.603$. The higher the score on the dimension of openness means that participants are increasingly interested in discussing abstract theories or ideas, discussing various kinds of things (essence, history, explanation, etc.) about something, and reading poetry or seeing a work of art. 
Conscientiousness dimension; the example of the conscientiousness dimension is: "I am a bit reckless/careless in arranging things well and neatly" (negative), "I am a person who lacks discipline (does not like being limited by time)" (negative), and "when I make commitment/promise with the authorities (supervisor/teacher), I always fulfil / fulfil it well". The twelve items in the conscientiousness dimension have internal consistency $(\alpha)$ of $=0.809$. The higher the score on the conscientiousness dimension, the better and tidy participants in arranging items, discipline, or commitment/promises with the authorities (supervisor/teacher).

Extraversion dimension; examples of items in the extraversion dimension are: "I am a warm and easy to associate", "I am the type of person who is cheerful and full of enthusiasm", and "I like entertainment places full of crowds". The twelve items in the Extraversion dimension have internal consistency $(\alpha)$ of $=0.815$. The higher the score on the Extraversion dimension, the participants will be warmer and more sociable, cheerful and full of enthusiasm, or like entertainment places full of crowds.

The dimension of Agreeableness; examples of items in the Agreeableness dimension are: "I do not want to be too generous to others" (negative), "I am a person who likes to help voluntarily", and "usually, I find it difficult to accept/follow opinions from others". The twelve items in the Agreeableness dimension have internal consistency $(\alpha)$ of $=0.659$. The higher the score on the Agreeableness dimension, the more generous participants will be to others, happy to help voluntarily, or accept or follow the opinions of others.

Neuroticism dimension; examples of the dimensions of the Neuroticism are: "I often feel depressed (easily stressed)", "I often experience feelings of disappointment", and "I often feel powerless (lack of enthusiasm)". The twelve items in the dimensions of Neuroticism have internal consistency $(\alpha)$ of $=0.814$. The higher the score on the dimension of Neuroticism, the more often participants feel depressed (easily stressed), often experience feelings of disappointment, or often feel less empowered (less excited).

\section{FINDINGS AND DISCUSSIONS}

\subsection{Findings}

\subsubsection{Construct validity (convergent evidence) of Kuder's preference records 2011-version and big five NEO PI-R}

Based on the results of the Spearman Correlation test in Table 1, KPR V.2011 measurement results (artistic, social service, literary, clerical, scientific, and persuasive) correlated with the results of the NEO PI-R measurement results. However, four areas of interest are uncorrelated KPR V.2011, namely the areas of musical, outdoor, mechanical, and computational interest.

The area of artistic interest is positively correlated with the personality aspect of openness, rs $(263)=0.204$, $p<0.01$. This indicates that the measurement results of KPR V.2011 (the area of artistic interest) and the results of the NEO PI-R (openness) measurement have construct validity (convergent evidence)

The area of interest in social service has the highest correlation with the aspect of agreeableness personality at a significant level of 0.01 , rs $(263)=0.313$. This indicates that the measurement results of KPR V.2011 (the area of interest in social service) and the results of the NEO PI-R (agreeableness) measurement have convergent evidence.

The area of literary interest has the highest correlation with the personality aspect of openness rs $(263)=0.233$, p < 0.01 . This indicates that the measurement results of KPR V.2011 (the area of literary interest) and the results of the NEO PI-R (openness) measurement have a construct validity (convergent evidence).

The area of clerical interest has the highest correlation with the personality aspect of openness rs $(263)=-0.232$, $\mathrm{p}<0.01$. This indicates that the measurement results of KPR V.2011 (the area of clerical interest) and the results of the measurement of NEO PI-R (openness) have construct validity (convergent evidence).

The area of scientific interest is positively correlated with the personality aspect of openness, rs $(263)=0.186, p<$ 0.01 . This indicates that the results of the KPR V.2011 measurement (the area of scientific interest) and the results of the NEO PI-R (openness) measurement have a construct validity (convergent evidence).

The area of persuasive interest has the highest correlation with extraversion, rs $(263)=0.378, \mathrm{p}<0.01$. This indicates that the results of the KPR measurement (the area of interest in persuasion) and the results of the measurement of NEO PI-R (extraversion) have construct validity (convergent evidence). 
Table 1 Correlations between Kuder's preference records 2011-version (KPR V.2011) and NEO PI-R (N=264)

\begin{tabular}{lccccc}
\hline \multirow{2}{*}{ KPR V.2011 } & \multicolumn{5}{c}{ NEO PI-R } \\
\cline { 2 - 6 } & $\begin{array}{c}\text { Openness to } \\
\text { Experience }\end{array}$ & Conscientiousness & Extraversion & Agreeableness & Neuroticism \\
\hline Artistic & $0.204^{* *}$ & -0.046 & 0.015 & 0.062 & 0.019 \\
Social Service & $0.174^{* *}$ & 0.120 & $0.197^{* *}$ & $0.313^{* *}$ & -0.024 \\
Literary & $0.233^{* *}$ & $-0.138^{*}$ & -0.054 & $-0.193^{* *}$ & 0.039 \\
Clerical & $-0.232^{* *}$ & $0.142^{*}$ & -0.053 & -0.093 & 0.073 \\
Scientific & $0.186^{* *}$ & 0.134 & -0.067 & -0.002 & -0.082 \\
Musical & 0.101 & -0.106 & -0.011 & -0.099 & 0.074 \\
Outdoor & -0.034 & -0.055 & -0.029 & 0.051 & -0.043 \\
Mechanical & -0.054 & -0.039 & 0.017 & 0.007 & 0.009 \\
Persuasive & 0.061 & -0.020 & $0.378^{* *}$ & -0.010 & $-0.237^{* *}$ \\
Computational & -0.092 & 0.102 & 0.039 & 0.053 & -0.107 \\
\hline
\end{tabular}

*) $\mathrm{p}<0.05 ; * *) \mathrm{p}<0.01$

\subsubsection{Construct validity (convergent evidence) of Kuder's preference records 2011-version and big five NEO PI-R}

In Table 2, it appears that some areas of interest in the KPR V.2011 measurment results have a significant relationship to the area of interest in Holland's VPI measurement results. The interest in artistic (KPR V.2011) has the highest positive correlation with artistic area of interest (Holland's VPI), rs $(263)=0.453, \mathrm{p}<0.01$. This indicates that the results of the KPR V.2011 measurement (the area of artistic interest) and Holland's VPI measurement results (the area of artistic interest) have convergent evidence. The area of social service (KPR V.2011) interest has the highest positive correlation with the social area of interest (Holland's VPI), rs (263) = $0.489, \mathrm{p}<0.01$. This indicates that the results of KPR V.2011 measurements (the area of social service interest) and Holland's VPI measurement results (social interest areas) have constructive validity (convergent evidence). Clerical interest (KPR V.2011) has the highest positive correlation with conventional area of interest (Holland's VPI), rs $(263)=0.389, p<0.01$. This indicates that the KPR V.2011 measurement results (the area of clerical interest) and Holland's VPI measurement results (conventional areas of interest) have construct validity (convergent evidence).

The area of interest in scientific (KPR V.2011) has the highest positive correlation with the investigative area of interest (Holland's VPI), rs $(263)=0.505, \mathrm{p}<0.01$. This indicates that the results of the KPR V.2011 measurement (the area of Scientific interest) and Holland's VPI measurement results (the area of investigative interest) have convergent evidence. Mechanical interest (KPR V.2011) has a positive correlation with realistic area of interest (Holland's VPI), rs $(263)=0.410, \mathrm{p}<0.01$. This indicates that the KPR V.2011 measurement results (areas of mechanical interest) and Holland's VPI measurement results (realistic areas of interest) have construct validity (convergent evidence). Persuasive interest (KPR V.2011) has the highest positive correlation with the enterprising area of interest (Holland's VPI), rs $(263)=0.321, \mathrm{p}<0.01$. This indicates that the results of KPR V.2011 measurements (areas of persuasive interest) and Holland's VPI measurement results (enterprising interest areas) have convergent evidence. Also, the area of interest in literary (KPR V.2011) also has a positive correlation with the investigative area of interest (Holland's VPI), rs (263) = $0.280, \mathrm{p}<0.01$. This indicates that the results of KPR V.2011 measurement (literary interest area) and Holland's VPI measurement results (investigative interest area) have convergent evidence. Musical interest (KPR V.2011) has a positive correlation with the artistic area of interest (Holland's VPI), rs $(263)=0.407, \mathrm{p}<0.01$. This indicates that the KPR V.2011 measurement results (musical interest area) and Holland's VPI measurement results (the artistic interest area) have convergent evidence. Computational interest (KPR V.2011) has a positive correlation with the investigative area of interest (Holland's VPI), rs $(263)=0.176, p<0.05$. This indicates that the KPR V.2011 measurement results (areas of interest computational) and Holland's VPI measurement results (the area of investigative interest) has convergent evidence. Meanwhile, the area of interest in outdoor (KPR V.2011) does not show any correlation with any aspect of Holland's VPI. This indicates that KPR V.2011, especially the area of outdoor interest, has aspects of the KPR V.2011 measurement results (area of outdoor interest) and Holland's VPI measurement results do not have construct validity (convergent evidence). 
Table 2 Correlations between Kuder's preference records 2011-version (KPR V.2011) and Holland's Vocational Preference Inventory (VPI)

\begin{tabular}{lcccccc}
\hline \multirow{2}{*}{ KPR V.2011 } & \multicolumn{5}{c}{ Holland's VPI } \\
\cline { 2 - 7 } & Realistic & Investigative & Artistic & Social & Enterprising & Conventional \\
\hline Artistic & $0.151^{*}$ & 0.032 & $0.453^{* *}$ & $0.153^{*}$ & 0.066 & 0.075 \\
Social Service & $-0.150^{*}$ & $0.157^{*}$ & $0.173^{*}$ & $0.489^{* *}$ & $0.166^{*}$ & 0.078 \\
Literary & -0.095 & $0.280^{* *}$ & 0.128 & 0.118 & -0.082 & $0.203^{* *}$ \\
Clerical & -0.123 & $-0.180^{* *}$ & $-0.252^{* *}$ & $-0.142^{*}$ & 0.003 & $0.389^{* *}$ \\
Scientific & 0.115 & $0.505^{* *}$ & 0.112 & $0.253^{* *}$ & 0.016 & -0.038 \\
Musical & 0.051 & 0.099 & $0.407^{* *}$ & 0.130 & -0.029 & 0.022 \\
Outdoor & -0.036 & -0.052 & -0.084 & 0.000 & -0.072 & -0.101 \\
Mechanical & $0.410^{* *}$ & 0.118 & -0.075 & -0.071 & 0.076 & 0.058 \\
Persuasive & -0.037 & 0.086 & -0.530 & $0.182^{* *}$ & $0.321^{* *}$ & 0.022 \\
Computational & 0.074 & $0.176^{*}$ & -0.132 & -0.116 & 0.116 & -0.074 \\
\hline
\end{tabular}

*) $\mathrm{p}<0.05 ; * *) \mathrm{p}<0.01$

\subsubsection{Kuder's interests profiling in social sciences}

In Table 3, the three highest area of interest are social service, computational, and musical, while for the three lowest area of interest are mechanical. This indicates that if someone wants to enter the social science department at a university, the scores of interest that must stand out when given a test using KPR V.2011 are social service, computational, and musical.

Table 3 Profile of Kuder's interests in participants of social sciences major

\begin{tabular}{ccccc}
\hline KPR & Minimum & Maximum & Mean & Std. Deviation \\
\hline Artistic & .00 & 14.00 & 4.8525 & 3.67803 \\
Social Service & 1.00 & 16.00 & 8.2623 & 4.01207 \\
Literary & .00 & 16.00 & 3.6885 & 3.71278 \\
Clerical & .00 & 15.00 & 4.9836 & 3.88369 \\
Scientific & 1.00 & 15.00 & 5.1803 & 3.17022 \\
Musical & .00 & 17.00 & 6.0000 & 4.53505 \\
Outdoor & .00 & 15.00 & 5.9508 & 3.48055 \\
Mechanical & .00 & 9.00 & 2.0820 & 2.48526 \\
Persuasive & .00 & 12.00 & 5.0164 & 3.17013 \\
Computational & .00 & 14.00 & 6.0820 & 3.41709
\end{tabular}

\subsection{Discussion}

This study aims to get a psychometric property (construct validity) measurement instrument for KPR V.2011. The construct validation study is conducted by analyzing the correlation between aspects of the area of interest KPR V.2011 with two variables: personality trait and Holland's VPI interest aspect. Also, in the descriptive study analysis (profiling) was carried out on participants from the social science department, as the first step of criterion validation study of KPR V.2011 measurement tools. 


\subsubsection{Kuder's preference records and personality}

\subsubsection{Openness to experience, literary, and clerical}

Based on the results of the analysis, KPR V.2011 can be predicted based on five personality traits, namely: openness to experience, conscientiousness, extraversion, agreeableness, and neuroticism. Openness to experience is positively correlated with the areas of literary, artistic, scientific, and social service interests; and negatively correlated with clerical. Individuals with traits of openness to experience personality tend to be open to various thoughts and tend to be critical of traditional values. If the aspects of scientific, artistic, social service, and clerical interests in KPR V.2011 are identified with aspects of investigative, artistic, social, and conventional interests in Holland's VPI, the results of this study are similar to the results of previous studies [6]. If the results of the study Wille et al. [6] compared with the results of current research, there are aspects of unexplained areas of interest based on openness to experience personality traits, namely literary. In KPR V.2011 certain interest areas (literary) can be predicted (have criterion-related validity) based on the trait of openness to experience personality.

\subsubsection{Conscientiousness, clerical, and literary}

The relationship of conscientiousness personality is positively correlated with clerical and negatively correlated with literary. It can be interpreted that individuals with conscientiousness personality traits who tend to be regular, neat, disciplined with time, prefer activities that are clerical, but avoid writing and reading activities. The results of the correlation of aspects of the area of interest in this study with conscientiousness personality traits are somewhat different from the results of previous studies [6]. In this study, only one aspect of the area of interest is clerical, which is related to the personality trait of conscientiousness. The correlation results are identical with the results of the correlation between aspects of conventional interest in Holland's VPI [6] and conscientiousness personality trait. Meanwhile, aspects of the area of interest in the measurement of other KPR V.2011, namely: scientific, artistic, social service, and persuasive, there is nothing related to the relationship of conscientiousness personality as aspects of the area of interest in Holland's VPI, namely: investigative, artistic, social, and enterprising in the results of research by Wille et al. [6]. However, in this study, the results of the conscientiousness personality trait can predict aspects of certain areas of interest which have not been explained to Holland's VPI, namely aspects of the area of interest in literary.

\subsubsection{Extraversion and persuasive}

The trait of extraversion personality is positively correlated with aspects of areas of interest in persuasion and social service. The higher the extraversion personality trait score or the more individual shows assertive, friendly, friendly, and easy to interact tendencies, the more individuals choose activities to persuade or influence others, and choose activities related to service to others. The results of this correlation are in line with the results of research by Wille et al. [6], especially in the aspect of persuasive interest, which is identical to the aspect of enterprising interest in Holland's VPI interest. Aspects in social service interest in KPR V.2011, which are identical to the aspects of the area of social interest in Holland's VPI, in this study are more correlated with the traits of extraversion personality, compared with the research of Wille et al. [6].

\subsubsection{Agreeableness, social service, and literary}

The agreeableness personality traits are positively correlated with aspects of the area of interest in social service and are negatively correlated with aspects of the area of interest in literary. The higher the agreeableness personality trait score, which is characterized by the tendency to be sincere, compromised, gentle, and easy to trust others, the more individuals choose social activities (teaching, service, etc.). If the aspect of social service interest in KPR V.2011 is identical to the aspect of social interest in Holland's VPI, the results of this study are the same as those of Wille et al. [6]. Things that have not been explained in Wille et al. [6] is an agreeableness personality trait that can predict aspects of literary interest. Where the higher the agreeableness personality trait score, the more individuals have less interest in activities such as reading, writing, or things related to literature. Another difference from the results of this study with the results of research by Wille et al. [6] are aspects of the area of scientific interest and persuasion in KPR V.2011 unlike the aspects of investigative and enterprising interest in Holland's VPI which can be predicted by the agreeableness personality trait.

\subsubsection{Neuroticism and Persuasive}

Trait of neuroticism personality is negatively correlated with persuasion. Individuals with high scores of neuroticism personality traits tend to display traits such as unstable emotions (irritability, sadness, anxiety), worry about other people's judgments about themselves, and often difficulties when facing stress or psychological distress. The higher the score of the trait of neuroticism personality, the lower the individual score on aspects of the area of interest in persuasion. This means that the more individuals do not choose activities such as convincing others to buy a product or make others interested in something. The results of this study are in line with the results of research by Wille et al. [6], if the aspect of 
persuasion interest in KPR V.2011 is identical with the aspect of enterprising interest in Holland's VPI. However, there are few differences in the results of this study with the results of the study by Wille et al. [6] namely in the aspects of artistic, scientific, and social service interests. These three aspects of the area of interest are not like the area of artistic, investigative, and social interests in Holland's VPI which can be predicted by traits of neuroticism personality.

\subsubsection{Kuder's preference records and Holland's vocational preference inventory}

In general, it can be said that the measurement of interest by using KPR V.2011 and Holland's VPI has convergent evidence, especially in the six aspects of the area of interest. The six aspects of interest in KPR V.2011 are: mechanical, scientific, artistic, social service, persuasive, and clerical convergent with six aspects of the realm of realistic, investigative, artistic, social, enterprising, and conventional interests in Holland's VPI. It appears that the highest correlation in the aspect of interest in KPR V.2011 with aspects of Holland's VPI interest can be described as follows: mechanical with realistic; scientific with investigative; social service with social; artistic artistic; persuasive enterprising; and clerical with conventional.

Outside of the six aspects above, there are four other aspects of KPR V.2011 namely: musical, computational, outdoor, and literary. If KPR V.2011 is considered to have an incremental value compared to Holland's VPI, the four aspects of interest in KPR V.2011 should not be correlated with low aspects of the area of interest measured by Holland's VPI. However, from the four aspects of the area of interest of KPR V.2011, not all of the four aspects have discriminant evidence against Holland's VPI. Only three aspects of the area of interest, namely: outdoor, computational, and literary, which are not correlated or have a low correlation with the aspects of Holland's VPI interest. One aspect of the area of interest, namely musical correlates quite highly with aspects of the area of artistic interest in Holland's VPI. Nevertheless, it can still be said that the KPR V.2011 measuring instrument has discriminant evidence (construct validity) with Holland's VPI measuring instrument.

\subsubsection{Interest profile in social sciences major}

Students majoring in social sciences have the highest KPR V.2011 scores in the area of interest in social services (teaching disadvantaged children, teaching Indonesian to illiterate mothers, and participating in community activities); computational (tinkering with mathematical formulas (story problems), being calculating experts, and teaching arithmetic); and musical (mastering several musical instruments, deepening skills in music, and establishing music schools). Students who choose social science majors may basically like service activities or community service. By choosing a social science major, the preference for these activities can be realized. In addition to the preference for social service activities, students majoring in social sciences basically need a preference for the computational area. In the social sciences department, the preference for the computational area is one of the capital to succeed in various courses, especially statistics, measurement, or quantitative methodology. Based on data analysis, social science students seem to like the area of musical interest. This interest becomes a means or media for students majoring in social science to conduct various service activities or the application of social sciences. According to Liljeström, Juslin, and Västfjäll [19], social context contributes to emotional intensity; when you hear a song. That is, the preference for the area of musical interest will be increasingly felt emotionally when individuals are in a social environment. In other words, it can be understood that individuals who like music will choose social science majors (as a realization of social situations) that they need to generate positive feelings.

\section{CONCLUSIONS}

In this study, psychometric properties (construct validity) were obtained from the KPR V.2011 measurement tool. The analysis results show that KPR V.2011 has convergence evidence on personality traits and aspects of Holland's VPI interest. Three aspects of interest in KPR V.2011 (outdoor, computational, and literary) have discriminant evidence on aspects of Holland's VPI interest. As the first step of criterion validation study, KPR V.2011 measurement tool produced profile profile of interest aspects from participants of social science majors.

\section{ACKNOWLEDGMENT}

This work was supported by Ministry of Research, Technology, and Higher Education Republic of Indonesia and Department of Research and Social Service Universitas Tarumanagara.

\section{REFERENCES}

[1] Institut Teknologi Sumatera. "Inilah dampak ketika anda salah memilih jurusan pada saat masuk perguruan tinggi negeri". Itera. http://usm.itera.ac.id/dampaksalah-memilih-jurusan/ (Accessed in May 11th, 2017).

[2] D. G. Zytowski, "The origins and development of frederic kuder's preference record", Journal of Career Assessment, vol. 23, no. 4, pp. 686-692, 2018, DOI: $10.1177 / 1069072714553568$. 
[3] D. G. Zytowski. "The predictive validity of the kuder preference record over a 25-year." Kuder. https://www.kuder.com/about/history-legacy/

(Accessed in September 30, 2018)

[4] P. T. Y. S. Suyasa. "Adaptasi alat ukur minat Kuder's Preferences Inventory/Records." Research Gate. (Accessed February 25th, 2017) https://www. researchgate.net/publication/260752302_Modifikasi_Al at_Ukur_Minat_-_Kuder_Preference_Inventory _Record

[5] M. R. Barrick, M. K. Mount, and R. Gupta, "Metaanalysis of the relationship between the five-factor model of personality and Holland's occupational types", Personnel Psychology, vol. 56, pp. 45-74, 2003. doi: 10.1111/ j.1744-6570.2003.tb00143.x.

[6] B. Wille, F. De Fruyt, S. A. Dingemanse, and J. Vergauwe, "A closer look at the psychological diversity within Holland interest types: Construct validation of the Career Insight Questionnaire", Consulting Psychology Journal: Practice and Research, vol. 67, no. 3, pp. 234-257, 2015, https://doi.org/10.1037/ cpb0000041.

[7] P. T. Costa, and R. R. McCrae, "Normal personality assessment in clinical practice: The NEO Personality Inventory", Psychological Assessment, vol. 4, no. 1, pp. 5-13, 1992, DOI:10.1037/1040-3590.4

[8] D. C. Funder, The Personality Puzzle, 2nd ed. New York, NY, USA: Norton, 2001.

[9] R. Hogan, and R. J. Blake, Vocational Interests: Matching Self-Concept with the Work Environment, K. R. Murphy, Ed. San Francisco, CA, USA: Jossey-Bass, 1996.

[10] J. L. Holland, Making Vocational Choices: A Theory of Vocational Personalities and Work Environments, 3rd ed. Odessa, FL, USA: Psychological Assessment Resources, 1997.

[11] K. S. D. Low, M. Yoon, B. W. Roberts, and J. Rounds, "The stability of vocational interests from early adolescence to middle adulthood: A quantitative review of longitudinal studies" Psychological Bulletin, vol. 131, pp. 713-737, 2005, DOI:10.1037/0033-2909. 131.5.713.

[12] R. W. Lent, S. D. Brown, and G. Hackett, "Contextual supports and barriers to career choice: A social cognitive analysis", Journal of Counseling Psychology, vol. 47, pp. 36-49, 2000, DOI:10.1037/ 0022-0167.47.1.36
[13] N. S. Cole, and G. R. Hanson, "An analysis of the structure of vocational interests". Act Research Report, vol. 40, no. 5, pp. 478-486, 1971, https://doi.org/10. $1037 / \mathrm{h} 0031513$

[14] J. L. Holland, "A theory of vocational choice", Journal of Counseling Psychology, vol. 6, pp. 35-45, 1959, DOI:10.1037/h0040767.

[15] J. R. Edwards, "Person-environment fit in organizations: An assessment of theoretical progress", The Academy of Management Annals, vol. 2, pp. 167230, 2008, DOI:10.1080/19416520802211503.

[16] C. H. Van Iddekinge, D. J. Putka, and J. P. Campbell, "Reconsidering vocational interests for personnel selection: The validity of an interest-based selection test in relation to job knowledge, job performance, and continuance intentions", Journal of Applied Psychology, vol. 96, no. 1, pp. 13-33, 2011, https://doi.org/10.1037/a0021193.

[17] I. Telvisia, and P. T. Y. S. Suyasa, "Kesesuaian minat terhadap pekerjaan: Pegawai produktif. Studi pada agen asuransi jiwa di Jakarta", Jurnal Phronesis, vol. 10, no. 1, pp. 76-95, 2008.

[18] D. A. C. Donnay, and F. H. Borgen, "The incremental validity of vocational self-efficacy: An examination of interest, self-efficacy, and occupation", Journal of Counseling Psychology, vol. 46, no. 4, pp. 432-447, 1999, http://dx.doi.org/10.1037/0022-0167.46. 4.4321 .5

[19] S. Liljeström, P. N. Juslin, and D. Västfjäll, "Experimental evidence of the roles of music choice, social context, and listener personality in emotional reactions to music", Psychology of Music, pp. 1-21, 2012, DOI: 10.1177/0305735612440615 